Jurnal Ilmu Administrasi Publik (2019): 30-42

DOI: http://dx.doi.org/10.31289/publika.v7i1.2173

Jurnal Administrasi Publik

http://ojs.uma.ac.id/index.php/publikauma

\title{
Implementasi Program dan Pemanfaatan E-KTP Yang Terintegrasi Di Kabupaten Sambas
}

\author{
Dwi Septiyarini*, Resky Nanda Pranaka** \\ *Badan Penelitian dan Pengembangan Provinsi Kalimantan Barat, Pontianak, Indonesia \\ ${ }^{* *}$ Badan Penelitian dan Pengembangan Provinsi Kalimantan Barat, Pontianak, Indonesia
}

Diterima Februari 2019; Disetujui April 2019; Dipublikasikan Juni 2019

\begin{abstract}
Abstrak
Tujuan penelitian ini adalah untuk mendeskripsikan implementasi program dan pemanfaatan e-KTP yang terintegrasi di Kabupaten Sambas serta mengidentifikasi faktor penghambat dan pendukung dalam implementasi program dan pemanfaatan e-KTP yang terintegrasi tersebut. Penelitian dilaksanakan di Kabupaten Sambas yaitu pada Disdukcapil , BPJS, KUA Kecamatan Tekarang, Kecamatan Tekarang dan Desa Merubung. Penelitian bersifat deskriptif kualitatif. Pengumpulan data dilakukan dengan teknik wawancara. Teknik analisa dalam penelitian ini adalah analisis deskriptif. Hasil penelitian memperlihatkan bahwa peran pemerintah dalam memberikan pemahaman kepada masyarakat sangat baik, yaitu berupa sosialisasi yang gencar dilakukan hingga daerah perbatasan. Hal ini dibuktikan dengan jumlah persentase perekaman yang tinggi. Namun, keberhasilan tersebut masih menyisakan beberapa hambatan antara lain sumber daya manusia yang kurang memadai, minimnya alat perekaman, keterbatasan jaringan internet, sering terjadi pemadaman listrik, keterbatasan anggaran, keterbatasan blangko perekaman, jangkauan antar wilayah yang cukup jauh dan dialek penduduk perbatasan yang condong ke negara Malaysia sehingga susah untuk dibedakan serta struktur birokrasi yang panjang dalam proses pembuatan e-KTP. Pemanfaatan e-KTP belum optimal karena tidak didukung kuat oleh sinergitas aplikasi yang terintegrasi pada masing-masing lembaga pemerintahan dalam pelayanan publik.
\end{abstract}

Kata Kunci : e-KTP, e-Government, Implementasi Program, Integrasi Data

\begin{abstract}
The purpose of this research is to describe the implementation of integrated e-ID card program and utilization in Sambas district as well as to identify inhibiting and supporting factors in the implementation of integrated e-ID card program and utilization. The study was conducted in Sambas District, namely Disdukcapil, BPJS, KUA Tekarang Sub-District, Tekarang Sub-district and Merubung Village. The research is qualitative descriptive. Data collection was done by interview technique. Analysis technique in this research is descriptive analysis. The results show that the role of government in providing understanding to the community is very good, ie in the form of a vigorous socialization carried out to the border area. This is evidenced by the high percentage of recording. However, these successes still leave some obstacles such as inadequate human resources, lack of recording tools, internet network constraints, frequent power outages, budget constraints, limited recording templates, far-reaching regional coverage and border-leaning population dialects the country of Malaysia so difficult to distinguish and long bureaucratic structure in the process of making e-ID card. Utilization of e-ID card is not optimal because it is not supported strongly by the synergy of integrated application in each government institution in public service.
\end{abstract}

Keywords: e-ID Card, e-Government, Program Implementation, Data Integration.

How to Cite: Septiyarini Dwi Pranaka R,N. (2019) Implementasi Program Dan Pemanfaatan E-Ktp Yang Terintegrasi Di Kabupaten Sambas, , 7 (1) 2019: 30-42
*Corresponding author:
E-mail: ri2n.chemist @gmail.com
ISSN 2549-9165 (Print)
ISSN 2580-2011 (Online) 


\section{PENDAHULUAN}

Perkembangan Teknologi Informasi yang kian pesat menimbulkan peralihan sistem kerja dari yang bersifat manual ke sistem digital. Perubahan ini juga telah merubah cara pandang dalam melakukan berbagai kegiatan, salah satunya adalah pada kegiatan instansi pemerintah. Untuk itu suatu instansi pemerintah membutuhkan sistem informasi yang mendukung kebutuhannya dalam menciptakan efisiensi dan efektifitas kerja dalam rangka meningkatkan pelayanan kepada masyarakat. Sistem tersebut mendukung penyelenggaraan pemerintahan dengan prinsip eGovernment.

Dalam ruang lingkup e-Government , pemanfaatan penyelenggaraan pemerintahan berbasis ICT (Information and Communication Technology) diharapkan dapat menjadi sarana pendukung transformasi untuk mempercepat pertukaran informasi, menyediakan sarana layanan dan kegiatan transaksi pemerintah dengan warga masyarakat Government to Citizen (G2C), pelaku bisnis Government to Bussines (G2B), dan tentunya dengan pihak pemerintah sendiri Government to Government (G2G) sehingga, jangkauan akses responsif, efisien, dan transparasi. $\begin{array}{ccc}\text { Fungsi } & \text { dan } & \text { manfaat } \\ \text { penggunaan } & \text { e-KTP antara lain : (1) }\end{array}$ merupakan langkah strategis menuju tertib administrasi kependudukan yang mengamanatkan adanya identitas tunggal bagi setiap penduduk dan terbangunnya basis data kependudukan yang lengkap dan akurat, (2) mencegah adanya pemalsuan, (3) mencegah adanya penggandaan penggunaan KTP, (4) kebutuhan untuk mewujudkan keamanan negara, (5) meningkatkan pelayanan kepada masyarakat, (6) kartu bukti tanda penduduk Indonesia, (7) dapat dipakai sebagai kartu suara dalam pemilu, pilkada dan lain-lain, (8) pengidentifikasian untuk memecahkan suatu perkara kejahatan yang sulit seperti terorisme, pembobolan bank via ATM, pemilikan KTP ganda, dan lain-lain, (9) membuat pengembangan teknologi identifikasi semakin diperlukan, dan (10) lebih awet penggunaanya sampai 10 tahun. (Oktaf, 2011).

Namun pada kenyataannya, fungsi eKTP masih sebatas untuk identitas kependudukan saja, padahal di dalamnya terdapat bermacam data yang dapat dimanfaatkan dalam mengelola data kependudukan. Hal ini terbukti dengan masih ditemukan keterlambatan birokrasi pelayanan publik karena 
mempersoalkan kevalidan dan autentik data masyarakat yang mengurus dokumentasi pelayanan publik, misalnya jika seseorang mau mengurus kartu imigrasi harus mempunyai data dokumen surat dan kelengkapan dokumen kartu keluarga, padahal untuk memperoleh e-KTP seseorang sudah harus memiliki kartu keluarga. Hal yang sama juga terjadi pada pengurusan Surat Izin Mengemudi (SIM) juga harus mengisi lagi kelengkapan data kependudukan. (Amrizal, 2016)

Kabupaten Sambas merupakan salah satu daerah yang mendapat penghargaan oleh Kemendagri atas komitmen dan keberhasilan Bupati dalam penyelenggaraan pelayanan penerapan eKTP sehingga mencapai target perekaman e-KTP cepat dari batas waktu yang telah ditetapkan. Target yang diberikan untuk Kabupaten Sambas adalah 400 ribu wajib e-KTP. Mengacu kepada pendapat George C. Edward III (1980 : 10) ada 4 variabel yang mempengaruhi keberhasilan dan kegagalan implementasi tersebut. Empat faktor atau variabel tersebut adalah: (1) komunikasi; (2) sumber daya ; (3) disposisi (sikap) dan (4) birokratik. Komunikasi diartikan sebagai proses penyampaian informasi komunikator kepada komunikan. Informasi kebijakan perlu disampaikan agar pelaku kebijakan dapat mengetahui, memahami apa yang menjadi isu, tujuan, arah, kelompok sasaran kebijakan, agar para pelaku kebijakan dapat mempersiapkan dengan benar apa yang harus dipersiapkan dan lakukan untuk melaksanakan kebijakan. Agar apa yang menjadi tujuan dan sasaran kebijakan dapat dicapai sesuai dengan apa yang diharapkan.

Implementasi e-KTP sangat strategis untuk sisitem pelayanan publik yang integratif serta menjadi sumber daya informasi utama bagi pemerintah dalam rangka penyediaan informasi bagi masyarakat. Namun e-KTP belum diperlakukan sebagaimana fungsi dan manfaatnya, e-KTP hanya sebatas identitas saja. Komunikasi, sumber daya, disposisi dan birokratik dapat mempengaruhi keberhasilan dan kegagalan implementasi tersebut. Berdasarkan uraian latar belakang, maka rumusan masalah dalam penelitian ini adalah sebagai berikut:

1. Bagaimanakah implementasi program dan pemanfaatan e-ktp yang terintegrasi di Kabupaten Sambas?

2. Apa saja faktor penghambat dan pendukung dalam implementasi program dan pemanfaatan e-ktp yang terintegrasi di Kabupaten Sambas? 


\section{METODE PENELITIAN}

Penelitian dilaksanakan di kabupaten Sambas yaitu pada Dinas Pendudukan dan Pencatatan Sipil (Disdukcapil), Badan Penyelenggara Jaminan Sosial (BPJS), Kantor Urusan Agama (KUA) kecamatan Tekarang, kantor Kecamatan Tekarang dan Desa Merubung selama 5 bulan pada tahun 2016. Penelitian bersifat deskriptif kualitatif. Pengumpulan data dilakukan dengan teknik wawancara dengan pejabat di Dinas Kependudukan dan Pencatatan Sipil Kabupaten Sambas, Pejabat di Badan Penyelenggara Jaminan Sosial Kabupaten Sambas, Pejabat Kantor Urusan Agama Kecamatan Tekarang, Pejabat di Kecamatan Tekarang dan Aparat Desa Merubung. Teknik analisa dalam penelitian ini adalah analisis deskriptif.

\section{HASIL DAN PEMBAHASAN}

Pemerintah Indonesia dalam hal ini Kemendagri saat ini sedang melaksanakan program e-KTP berbasis Nomor Induk Kependudukan (NIK) nasional sebagai pelaksanaan UU no. 23 tahun 2006 tentang Administrasi Kependudukan. Hal-hal yang diatur dalam UU adalah sebagai berikut: Kemendagri berkewajiban dan bertanggung jawab menyelenggarakan administrasi kependudukan secara nasional; Pemerintah Propinsi berkewajiban dan bertanggung jawab menyelenggarakan administrasi kependudukan pada skala provinsi; Pemkab/Pemkot berkewajiban dan bertanggung jawab menyelenggarakan administrasi kependudukan pada skala kabupaten/kota yang dilakukan Bupati/Walikota; dan Dinas Dukcapil Kabupaten/Kota berkewajiban memberikan pelayanan pendaftaran penduduk dan pencatatan sipil, dan menerbitkan dokumen kependudukan. Program e-KTP berbasis NIK bertujuan untuk memperoleh tertib database dan tertib dokumen kependudukan (Kemendagri, 2011).

Pemerintah Kabupaten Sambas sampai dengan bulan September 2016 telah berhasil melakukan perekaman $93.94 \%$. Hal ini dapat dilihat pada tabel berikut ini :

Tabel 1. Laporan Perkembangan Penerapan KTP Elektronik di Kabupaten Sambas per September 2016.

\begin{tabular}{|c|c|c|c|c|c|c|c|}
\hline \multirow[b]{2}{*}{ No } & \multirow[b]{2}{*}{ Kecamatan } & \multicolumn{2}{|c|}{ Jumlah Rekam } & \multicolumn{2}{|c|}{ Belum Rekam } & \multicolumn{2}{|c|}{ Cetak } \\
\hline & & Jumlah & $\%$ & $\begin{array}{c}\text { Jumla } \\
\mathrm{h}\end{array}$ & $\%$ & Jumlah & $\%$ \\
\hline 1 & SAMBAS & 34,166 & 99.87 & 45 & 0.13 & 32,972 & 96.51 \\
\hline 2 & $\begin{array}{c}\text { TELUK } \\
\text { KERAMAT }\end{array}$ & 44,673 & 98.48 & 689 & 1.52 & 42,820 & 95.85 \\
\hline 3 & JAWAI & 25,977 & 88.67 & 3,318 & 11.33 & 24,791 & 95.43 \\
\hline 4 & TEBAS & 47,063 & 87.31 & 6,838 & 12.69 & 44,715 & 95.01 \\
\hline 5 & PEMANGKAT & 32,781 & 88.22 & 4,378 & 11.78 & 30,350 & 92.58 \\
\hline 6 & SEJANGKUNG & 16,043 & 96.04 & 661 & 3.96 & 15,369 & 95.80 \\
\hline 7 & SELAKAU & 21,051 & 91.64 & 1,921 & 8.36 & 20,238 & 96.14 \\
\hline 8 & PALOH & 17,095 & 106.12 & -986 & -6.12 & 17,099 & 100.02 \\
\hline 9 & $\begin{array}{c}\text { SAJINGAN } \\
\text { BESAR }\end{array}$ & 8,057 & 129.72 & $-1,846$ & -29.72 & 6,044 & 75.02 \\
\hline 10 & SUBAH & 13,086 & 102.00 & -257 & -2.00 & 12,390 & 94.68 \\
\hline 11 & GALING & 13,947 & 97.31 & 385 & 2.69 & 14,402 & 103.26 \\
\hline 12 & TEKARANG & 11,245 & 104.41 & -475 & -4.41 & 10,428 & 92.73 \\
\hline
\end{tabular}




$\begin{array}{lcccccc}13 & \text { SEMPARUK } & 17,105 & 78.67 & 4,638 & 21.33 & 17,538 \\ 14 & \text { SAJAD } & 8,477 & 97.18 & 246 & 2.82 & 8,156 \\ 15 & \text { SEBAWI } & 10,969 & 88.18 & 1,471 & 11.82 & 11,032 \\ & \text { JAWAI } & & & & & \\ 16 & \text { SELATAN } & 13,349 & 87.37 & 1,929 & 12.63 & 12,647 \\ & & & & & \\ 17 & \text { TANGARAN } & 14,882 & 95.77 & 657 & 4.23 & 14,735 \\ 18 & \text { SALATIGA } & 10,873 & 98.11 & 210 & 1.89 & 10,349 \\ & \text { SELAKAU } & & & & & \\ 19 & \text { TIMUR } & \mathbf{6}, 914 & 101.59 & -108 & -1.59 & 6,727 \\ & \text { TOTAL } & \mathbf{3 6 7 , 7 5 3} & \mathbf{9 3 . 9 4} & \mathbf{2 3 , 7 1} & \mathbf{6 . 0 6} & \mathbf{3 5 2 , 8 0 2}\end{array}$

Sumber : Database Disdukcapil

Kabupaten Sambas

Untuk menganalisis implementasi program e KTP di Kab Sambas adalah berdasarkan implementasi kebijakan Georce c. Edward III. Implementasi kebijakan ini dipengaruhi oleh faktor komunikasi, sumber daya, disposisi dan Birokrasi. Pengaruh keempat faktor tersebut dijabarkan sebagai berikut :

1) Komunikasi

Dalam implementasi program e-KTP Dinas Kependudukan dan Pencatatan Sipil (Disdukcapil) Kabupaten Sambas melaksanakan peran komunikasi dengan pihak kecamatan dan kelurahan. Komunikasi tersebut berkaitan dengan kemampuan Disdukcapil menyampaikan sosialisasi, dan juga melakukan koordinasi pelaksanaan e-KTP.

Sehubungan dengan program sosialisasi, Disdukcapil Kabupaten Sambas bersama-sama dengan Kecamatan Tekarang dan Desa Merubung telah melakukan sosialisasi kepada masyarakat. Sosialisasi tersebut dengan mengundang masyarakat ke kantor camat untuk diberi pengarahan $\prod_{96.21}^{102.53}$ henai e-KTP. Aparatur Desa dan Recamatan turut serta melakukan ${ }_{99.74}^{94.74}$ enataan dengan cara-cara persuasif ưntink mengajak masyarakat datang ke 97.30 kanktor kecamatan. Dengan sosialisasi tersebut masyarakat menjadi paham tata cara pengurusan e-KTP.

Selain Sosialisasi juga diadakan koordinasi melalui rapat antara Disdukcapil kabupaten Sambas dengan pihak Kecamatan Tekarang dan Desa Merubung.Koordinasi tersebut dilakukan dalam rangka percepatan proses perekaman e-KTP sehingga halhal yang dapat meghambat proses perekaman tersebut dapat segera teratasi.

2) Sumber Daya

Ketersediaan sumber daya merupakan salah satu faktor dalam keberhasilan suatu implementasi kebijakan. Sumber daya ini meliputi manusia, peralatan dan keuangan. Implementasi e-KTP di Kabupaten Sambas memiliki SDM yang kurang memadai, sebagian besar pegawai yang ada di Disdukcapil adalah pegawai kontrak.

Selain minimnya sumber daya manusia juga masih minimnya jumlah alat perekaman, jaringan internet yang terbatas serta sering terjadinya pemadaman listrik. Meskipun demikian 
pihak Disdukcapil Kabupaten Sambas telah memiliki pelayanan mobile berjumlah 4 buah.

\section{3) Disposisi}

Dalam pelaksanaan program e-KTP di Kabupaten Sambas, partisipasi masyarakat untuk mendatangi lokasi perekaman e-KTP cukup tinggi. Hal ini bisa terlihat dari capaian hasil perekaman e-KTP yang mencapai 93.94 \%. Keberhasilan tersebut juga masih terdapat kendala antara lain jarak antar wilayah memiliki jangkauan yang cukup jauh apalagi Kabupaten Sambas merupakan salah satu kabupaten perbatasan dengan negara Malaysia. Kendala tersebut yang dapat mengurangi antusiasme masyarakat untuk mendatangi proses perekaman.

Selain itu karena terletak pada daerah perbatasan, beberapa masyarakat secara dialek dan kebiasaan sehari-hari lebih cenderung ke Malaysia sehingga sangat sulit mengenali apakah warga tersebut warga Kabupaten Sambas ataukah warga Malaysia. Apalagi warga disekitar perbatasan masih banyak yang belum memiliki NIK (Nomor Induk Kependudukan). Untuk itu, Disdukcapil Kabupaten Sambas membuat sebuah Kebijakan untuk warga perbatasan apabila akan melakukan proses perekaman harus menyanyikan lagu Indonesia Raya dan juga menghafal Pancasila selain itu juga harus ada pendamping dari keluarga. Hal tersebut dilakukan untuk meminimalisir kesalahan dalam proses pembuatan eKTP.

4) Birokrasi program e-KTP dilakukan secara berjenjang. Dalam pelaksanaannya terdapat beberapa kendala antara lain penyediaan blangko perekaman dan hasil jadi e-KTP dilakukan oleh Kementerian Dalam Negeri untuk kemudian didistribusikan ke daerah. Hal tersebut dapat menyebabkan terjadinya keterlambatan dalam distribusi. Struktur birokrasi yang panjang juga menyebabkan proses pembuatan e-KTP menjadi tidak efisien. Pihak Disdukcapil Kabupaten Sambas berharap agar penyediaan blanko perekaman dan hasil jadi e-KTP dapat dilakukan di tingkat provinsi sehingga kekosongan blanko dan hasil e-KTP tidak terkendala oleh proses distribusi yang lama. Namun, peran pihak kecamatan dan juga aparat desa patut diapresiasi. Di tengah keterbatasan yang ada petugas kecamatan dan aparat desa mampu menjalankan tugasnya dengan baik. Bahkan apabila terjadi kerusakan alat perekaman di kecamatan, petugas 
kecamatan beserta aparat desa setempat mengkoordinasikan dan mendampingi masyarakat untuk melakukan proses perekaman di kantor Disdukcapil.

Hasil penelitian ini memperkuat teori George C.Edward III dan beberapa penelitian sebelumnya seperti Roni 92011), irfan (2013), Nazaruddin (2013) dan Margareta (2015) bahwa implementasi kebijakan dipengaruhi oleh 4 faktor yaitu komunikasi, sumber daya, disposisi dan birokrasi. Setiap Daerah memiliki potensi yang berbeda, bisa jadi faktor sumberdaya, birokrasi tersebut menjadi penghambat implementasi tetapi untuk daerah yang lain menjadi faktor pendukung tercapainya sebuah implementasi. Jadi, keberhasilan sebuah implementasi juga tergantung potensi daerah dan kebijakan yang diterapkan oleh masingmasing daerah.

Pemanfaatan teknologi informasi oleh birokrasi pemerintahan, dapat membantu memudahkan rangkaian pelayanan masyarakat yang meliputi penyimpanan dan pengelolaan informasi serta mekanisme penyampaian informasi dari penyelenggara kepada masyarakat dan sebaliknya dalam bentuk lisan dan tulisan serta disajikan secara manual maupun elektronik seperti data yang ada dalam e-ktp. Selain itu pemanfaatan teknologi informasi dalam proses pemerintahan akan meningkatkan efisiensi, efektifitas, transparansi dan akuntabilitas penyelenggaraan pemerintahan.

Implementasi database terdistribusi dapat menghasilkan kinerja yang baik menyangkut ketersediaan data. Replikasi database yang dapat menghasilkan kesamaan posisi data pada beberapa master site, memungkinkan pembagian beban akses ke server, sehingga kegagalan akses data minimal (Cinderatama, Yuwono, dan Asmara,2010). Pemanfaatan database kependudukan untuk e-Government dan beragam aplikasi sistem informasi di Pemkab/Pemkot sangat dimungkinkan mengingat SIAK online di setiap kecamatan langsung terhubung dengan data center kependudukan pusat di Ditjen Adminduk_melalui VPN dial. Hal itulah yang dilakukan oleh BPJS Kabupaten Sambas dan Kantor Urusan Agama (KUA) Kecamatan Tekarang yang sudah terintegrasi dengan data center kependudukan pusat.

a. Badan Penyelenggara Jaminan Sosial (BPJS) Kabupaten Sambas.

Pemanfaatan e KTP dan database kependudukan yang berbasiskan nomor induk kependudukan (NIK) oleh BPJS di 
lakukan di tahun 2014 melalui sebuah perjanjian kerjasama dengan Kementerian Dalam Negeri. Perjanjian kerja sama tersebut tertuang dalam Nomor 119/3502/DUKCAPIL dan Nomor 0116/KTR/0413 yang ditandatangani 15 April 2013 tentang Pemanfaatan Kartu Tanda Penduduk Elektronik dan Database Kependudukan yang berbasiskan Nomor Induk Kependudukan dalam layanan PT Askes (persero). (www.BPJS.go.id). Tujuan perjanjian kerjasama ini untuk mengefektifkan fungsi dan peran Kemendagri maupun BPJS dalam pemanfaatan e-KTP untuk mengefektifkan penyelenggaraan program jaminan kesehatan bagi masyarakat. Pada tahap awal e-KTP dimanfaatkan untuk mengefektifkan data kepersertaan peserta BPJS serta menjadi acuan untuk membentuk nomor tunggal kepesertaan BPJS, validasi dan verifikasi proses pelayanan klaim oleh peserta dan pembaharuan data kepesertaan. Selain itu pemanfaatan e-KTP juga akan digunakan untuk mengefektifkan perencanaan jaminan kesehatan bagi seluruh penduduk dengan menggunakan data agregat kependudukan.

Bentuk integrasi yang dimanfaatkan oleh BPJS adalah :

\section{Pemadanan Data}

a. Peserta Akses Aktif sebesar
16.356.819 rekord dengan hasil pemadanan 11.821 .498 rekord atau $\quad 72,3 \quad \% \quad$ berhasil dipadankan.

b. Peserta Jamkesnas sebesar 86.400.000 rekord dengan hasil 59.324.724 rekord atau $69 \%$ berhasil di padankan

2. Akses Data Secara Online Akses data kependudukan melalui web service untuk keperluan pendaftaran peserta baru dan verifikasi data peserta lama dengan rata- rata akses mencapai 10.000 akses perhari. Data Kependudukan yang dapat di akses saat ini terdiri dari 27 field dan dilengkapi data keluarga

3. Pemanfaatan Nomor Induk Kependudukan yang meliputi penyertaan NIK dalam dokumen/Kartu peserta dan penggunaan NIK sebagai basis pencarian dan verifikasi data penduduk dengan web service.

4. Pemanfaatan laporan statistik kependudukan sebagai sumber data agregat untuk melakukan analisa pemetaan sasaran calon peserta BPJS kesehatan.

5. Pemanfaatan card reader sebagai verifikasi keabsahan kepemilikan kartu tanda penduduk saat klaim di 
rumah sakit.

Sumber : dukcapil.kemendagri.go.id

Integrasi pemanfaatan database kependudukan dengan kebutuhan BPJS di atas dikemukakan oleh Kepala Cabang BPJS Kabupaten Sambas, seperti kutipan wawancara berikut :

"Dengan adanya program e-KTP ini sangat membantu proses pelayanan dalam BPJS, kita tidak perlu lagi menginput data kependudukan sehingga masyarakat yang akan melakukan pendaftaran tidak perlu lagi untuk fotocopy KTP. Hal tersebut tentunya membantu memudahkan rangkaian pelayanan masyarakat... BPJS telah terintegrasi dengan Ditjen Kependudukan dan Pencatatan Sipil sejak tahun 2014. Hanya saja integrasi tersebut hanya dilakukan dengan pemerintah pusat... Untuk integrasi dengan Dinas Kependudukan dan Pencatatan Sipil (Disdukcapil) Kabupaten Sambas belum ada sehingga kita kesulitan dalam proses penginputan data bayi baru lahir karena data bayi baru lahir belum terinput di pusat.Dalam penginputan data bayi baru lahir yang bisa kita lakukan adalah menunggu akta kelahiran yang dikeluarkan oleh Disdukcapil Kabupaten Sambas itu jadi. Proses pelayanan mulai dari proses pendaftaran sampai cetak kartu BPJS adalah selama 14 hari. Selama proses pelayanan berlangsung tidak ada hambatan yang berarti kecuali masalah jaringan internet yang terbatas menjadi hambatan dalam proses pelayanan kita."

b. Kantor Urusan Agama Kecamatan

Tekarang

Kantor Urusan Agama Kecamatan Tekarang juga sudah menerapkan eGovernment dengan pendaftaran pernikahan secara online dengan nama Sistem Informasi Manajemen Nikah
(SIMKAH), tetapi belum terintegrasi dengan dinas dukcapil kabupaten Sambas. Sehingga untuk membuktikan keakuratan data kependudukan warga yang akan melakukan pendaftaran nikah masih harus menyertakan fotocopy KTP. Tetapi hal tersebut tidak menutup kemungkinan untuk ke depannya akan di lakukan kerjasama dengan dinas dukcapil sehinnga pencatatan pernikahan di Kantor Urusan Agama (KUA) nanti akan di sinkronkan dengan KTP elektronik. Sehingga begitu mencatatkan pernikahan di KUA bisa langsung mengganti status di KTP elektronik. Hal ini merupakan terobosan layanan yang dapat menghindarkan terjadinya pemalsuan data. Ada beberapa kejadian karena kabupaten Sambas merupakan salah satu kabupaten yang dekat dengan negara Malaysia, banyak masyarakat yang mencari pekerjaan ke Malaysia. Karena ketika mengurus pernikahan status pada e-KTP masih tertulis belum menikah, ada beberapa yang akhirnya menikah lagi di negara Malaysia Hanya saja hal tersebut saat ini belum bisa diwujudkan oleh KUA Kecamatan Tekarang karena diperlukan anggaran yang besar dan juga sumber daya manusia yang tersedia masih terbatas terutama yang mengerti 
masalah informasi teknologi (IT) belum tersedia.

Integrasi layanan yang ada untuk saat ini hanya terbatas pada lingkup KUA dengan Kementerian Agama saja. Meskipun demikian KUA kecamatan Tekarang tetap konsisten untuk dapat memberikan pelayanan yang terbaik buat masyarakat. Batas pendaftaran pernikahan adalah 10 hari kerja sebelum pelaksanaan pernikahan. Hal itu dikarenakan agar pihak KUA dapat melakukan verifikasi data, apabila terjadi kesalahan sebelum input data dapat dikembalikan lagi untuk dapat diperbaiki. Sebab apabila terjadi kesalahan satu huruf pada akta nikah untuk memperbaikinya harus melalui proses pengadilan. Buku Nikah yang dulunya ditulis tangan sekarang juga sudah berubah dalam bentuk print.

Berikut adalah kutipan wawancara dengan Kepala Kantor Urusan Agama Kecamatan Tekarang . " Proses pelayanan di disini sudah secara online yaitu dengan Sistem Informasi Manajemen Nikah (SIMKAH) yang bisa diakses diseluruh Indonesia. Calon pengantin bisa langsung mengecek apakah datanya sudah di entri ataukah belum. Dengan adanya sistem itu sangat membantu proses pelayanan disini, apalagi sekarang sudah e-KTP. Namun masyarakat juga harus diberikan pemahaman karena batas waktu pendaftaran menikah 10 hari kerja. Hal ini memberikan ruang apabila terjadi kesalahan dapat dikembalikan ke calon pengantin untuk dilengkapi sebelum entri data dilakukan., kalau dulu dalam jangka 1-3 bulan sekarang cukup 10 hari saja. Masyarakat sekarang harus patuh mengikuti aturan, tidak bisa juga pengajuan nikah dilakukan 3 hari sebelum hari pelaksanaan. Apabila itu terjadi harus minta surat rekomendasi dari kecamatan disertai dengan alasan yang kuat. Saat melakukan pendaftaran pernikahan calon pengantin harus menyertakan fotokopi kartu keluarga, KTP untuk keakuratan data sebelum kita entri.. belum ada integrasi antara Disdukcapil Kabupaten Sambas, tetapi tidak menutup kemungkinan kedepannya akan kita lakukan. Setelah menikah status di KTP akan langsung berubah. Hal itu perlu dilakukan karena banyak warga disini yang bekerja di Malaysia, karena status di KTP tidak langsung berubah ada beberapa kejadian mereka menikah lagi .Hanya saja itu belum bisa kita lakukan karena butuh dana yang besar dan juga kita tidak memiliki tenaga IT."

Wujud Pelaksanaan e-Government juga terlihat di desa Merubung. Meskipun belum terintegrasi langsung dengan dinas dukcapil Kabupaten Sambas, proses pelayanan terhadap masyarakat desa tersebut telah memiliki terobosan inovasi sistem pelayanan elektronik dengan memanfaatkan nomor induk kependudukan (NIK). Sistem tersebut berisi semua data kependudukan warga desa Merubung, sehingga warga masyarakat sangat terbantu dengan sistem pelayanan tersebut.

Hal berbeda terjadi pada Disdukcapil Kabupaten Sambas, 
database kependudukan antara kecamatan dengan disdukcapil belum terintegrasi. Demi mewujudkan pelayanan publik yang berbasis elektronik tersebut Disdukcapil Kabupaten Sambas membentuk satu bidang baru yaitu bidang inovasi. Dengan terbentuknya bidang ini diharapkan integrasi database kependudukan dengan kecamatan dapat segera terwujud. Hal mendasar yang menyebabkan integrasi tersebut belum dapat segera terwujud adalah keterbatasan anggaran serta belum memadainya sumber daya manusia yang ada.

Resistensi terhadap perubahan sebagai penyebab faktor penghambat dalam e-Government bisa terjadi sebagai akibat dari adanya: 1) ego sektoral organisasi sehingga menutup kemungkinan untuk mau diatur atau bekerjasama dengan organisasi lain; 2) anggapan bahwa sistem informasi merekalah yang terbaik dibanding lainnya; 3) konteks kepentingan yang berbeda pada setiap organisasi sehingga sulit dicari titik temu untuk melakukan integrasi secara cepat; 4) keinginan untuk menjadi pimpinan tim integrasi dalam konsorsium kerja sama; 5) ketidakinginan untuk saling membagi data/informasi/pengetahuan karena dianggap mengurangi keunggulan kompetitif individu/organisasi; 6) ketidaktahuan memulai integrasi dari mana sehingga kondusif untuk dilakukan sejumlah pihak terkait; dan lainnya (Indrajit, 2006).

\section{KESIMPULAN}

Dari hasil dan pembahasan yang telah dikemukakan dan mengacu pada tujuan yang hendak dicapai melalui penelitian ini adalah peran pelayanan public sangat penting dalam penggunaan KTP elektronik yaitu :

a. Disdukcapil Kabupaten Sambas dalam implementasi program e-KTP secara umum sudah berjalan optimal. Capaian hasil perekaman per september 2016 mencapai $93.94 \%$.

b. Keberhasilan tersebut juga masih menyisakan beberapa hambatan antara lain sumber daya manusia yang kurang memadai, minimnya alat perekaman, keterbatasan jaringan internet, sering terjadi pemadaman listrik, keterbatasan anggaran, keterbatasan blangko perekaman, jangkauan antar wilayah yang cukup jauh dan dialek penduduk perbatasan yang condong ke negara malaysia. Sementara itu, faktor pendukung yang menentukan keberhasilan implementasi e-KTP tersebut adalah tingginya rasa 
tanggung jawab dari Disdukcapil, Kecamatan dan Aparat Desa. Di tengah keterbatasan yang ada mereka mampu menjalankan tugas dengan baik. Selain itu partisipasi masyarakat juga cukup tinggi untuk mendatangi tempattempat perekaman.

c. Pemanfaatan e-KTP di Kabupaten Sambas belum Optimal. BPJS kabupaten Sambas dan KUA Kecamatan Tekarang sudah melaksanakan sistem pelayanan online tetapi sistem pelayanan online tersebut masih bersifat internal instansi tersebut, belum ada integrasi antar instansi yang ada di Kabupaten Sambas.

d. Belum adanya komitmen bersama dari pemangku jabatan di Kabupaten Sambas menjadi kendala belum terwujudnya e-Government. Selain itu juga keterbatasan anggaran, keterbatasan infrastruktur dan sumber daya manusia yang handal menajadi faktor utama.

\section{DAFTAR PUSTAKA}

Amrizal, Tukino, Abdul latif. 2016. Rekayasa Perangkat Lunak Sistem e-KTP Terintegrasi Birokrasi Umum Di Kota Batam. Jurnal TEKNOSI, Vol 02 No 02

Cinderatama, T.A Yuwono, W., Asmara, R. 2010. Basis Data Terdistribusi untuk Aplikasi Kependudukan berbasis Web. Penelitian Tugas Akhir, PEN-ITS

Edward III, G.C. 1980. Implementing Public Policy, Congressional Querterly Press.

Indrajid, R.E., 2006, Evolusi Strategi Integrasi Sistem Informasi Ragam Institusi, Kiat Memecahkan Permasalahan Politis dalam Kerangka Manajemen Perubahan, Prosiding KNTIK untuk Indonesia, ITB, 3-4 Mei 2006.

Irfan, S.2013. Electronic ID Card Program Implementation in Support EGovernment in Makassar. Jurnal Ilmiah Fak MP IPDN Vol 1 No 2

Margaretha. 2015. Implementasi Kebijakan Kartu tanda Penduduk Elektronik (KTP el) di Kecamatan Putussibau Utara Kabupaten Kapuas Hulu. TAPM UT

Nazaruddin.2013.Efektivitas Pelaksanaan Kebijakan Program e-KTP (Studi Pelaksanaan Data di Kabupaten Hulu Sungai Utara). Jurnal Ilmu Politik dan Pemerintahan Lokal, Volume II edisi 2

Oktaf, 2011. Seputar Kartu Tanda Penduduk Elektronik (e-KTP). Gunung Agung. Jakarta

Pascual, P.J., e-Government, e-Asean Task Force UNDP-APDIP. May 2003

Permendagri No.25 Tahun 2011. Pedoman Pengkajian Pengembangan Dan Pengelolaan Sistem Informasi Administrasi Kependudukan.

Raharjo, B., 2001. Membangun eGovernment, ITB 
Roni E.P, Tengku R.V. 2011. Implementasi Program KTP Elektronik (e-KTP) di Daerah Percontohan.MIMBAR vol XXVII no 2

Supangkat., SH., 2006. Framework Strategi Implementasi EGovernment, Prosiding KNTIK untuk Indonesia, ITB,

Sutanta, E. 2011. Model Integrasi Database Penduduk Indonesia Dengan berbagai Sitem Informasi Berbasis Komputer. Jurnal Informatika Vol 5 No 2

Sutanta, E., Ashari, A. 2012. Pemanfaatan Database Kependudukan Terdistribusi pada ragam Aplikasi Sistem Informasi di Pemerintah Kabupaten /Kota. Jurnal SISFOTENIKA, Volume 2 No 1

Tadu, P. 2014. Sistem Akses Kontrol Kunci Elektrik Menggunakan Pembacaan $e-K T P$.

UU No 23 Tahun 2006. Administrasi Kependudukan.

UU No 52 Tahun 2009. Perkembangan Kependudukan dan Pembangunan Keluarga.

Jakarta Post, 15 Januari 2003

www,Indonesia.go.id

www.BPJS.go.id

www.dukcapil.Kemendagri.go.id

www.Okezone.com, senin 15 april 2013 